\section{Obstetric fistula repair: a guide to patient selection}

\author{
Aniefiok J. Umoiyoho, \\ Emmanuel C. Inyang-Etoh
}

Department of Obstetrics and

Gynaecology, University of Uyo, Nigeria

\section{Abstract}

Objective. The World Health Organization has advocated the classification of obstetric fistula into simple and complex cases. This study set out to design a guide to patient selection to facilitate the attainment of this goal.

Materials and Methods. Associated risk factors were identified and analyzed among a cross section of women who had complex obstetric vesicovaginal fistulas.

Results. The risk factors that were identified to affect significantly the prospect of cure following repair were large size of the fistula greater than $4 \mathrm{~cm}$, associated urethral loss and adherence of the fistula to the pubic bone. Others were three or more previous attempts at repair, moderate to severe degree of scarring at the fistula margin, combined vesicovaginal and rectovaginal fistulas and the proximity of the fistula margin to the ureter. Each identified risk factor was allocated a score ranging from 0 to 4 depending on the adjudged capacity of the factor to affect the prospect of cure following repair.

Conclusions. Any case of vesicovaginal fistula with a total score of 4 or less using the proposed prognostic scoring system was adjudged suitable for repair by gynaecological or general surgeons, who have been trained on fistula repair with a significant prospect of success.

\section{Introduction}

Obstetric fistula continues to occur in developing countries of the world due to dearth of functional maternity services or failure of pregnant women to utilize available maternity services. In 1993, the World Health Organization estimated that approximately 2 million women lived with unrepaired obstetric fistula largely in poor-resource countries of Africa and south Asia. ${ }^{1}$ Forty percent of those women were said to be Nigerians. ${ }^{1}$ In 2001, 33,000 new cases of vesicovaginal fistula were estimated to be added annually to the prevalent population in sub-Saharan Africa. ${ }^{2}$ About 20,000 obstetric fistula cases is estimated to be added yearly to the prevalent population in Nigeria alone. $^{3}$

Following the high prevalence and increas- ing incidence of obstetric fistula in Nigeria, it will take several decades for the back-log of unrepaired cases of obstetric fistula to be cleared considering the United Nations revelation that barely 33 surgeons provide fistula repair services in Nigeria and that only about 2500 cases of obstetric fistula are repaired annually in the country. ${ }^{4}$

Obstetric fistula is a consequence of neglected obstructed labour; its presentation is variable but depends on the location, size, number and the status of the bladder continence mechanism. ${ }^{5,6}$ The factors that influence the outcome of repair include: the number of fistulas present, the number of previous attempts at repair, patient selection and preparation. Other factors are the surgical skill and experience of the surgeon as well as the postoperative care. ${ }^{6,7}$ The repair of obstetric fistulas does not require high technology; rather, the availability of a health facility with a standard operating theatre, basic surgical equipment and instruments as well as trained and dedicated health personnel suffice for successful fistula repair.

The World Health Organization has advocated the classification of obstetric fistula into simple and complex cases where simple cases can be repaired by non-expert fistula surgeons whereas complex fistulas should be referred to an expert fistula surgeon. ${ }^{8,9}$ Among the few contributions to the classification of obstetric fistula are those of Waaldijk, Goh and Browing. ${ }^{10-12}$ Nonetheless, these classifications and others are largely anatomical, descriptive and not based on practical evidence. This drawback limits their use in patient selection and case prognostication before repair.

The proposed prognostic scoring system is based on our experience with the repair of obstetric fistulas with variable degrees of complexity. We believe that the scoring system can help in the selection of simple cases of vesicovaginal fistula suitable for repair by gynaecological or general surgeons, who have been trained on fistula repair. It is envisaged that this strategy would help in the drive to reduce the number of women living with unrepaired obstetric fistula in parts of the world where obstetric fistula is prevalent. In addition, more surgeons could be mobilized and trained to repair simple cases while complex cases are referred to the few available expert fistula surgeons.

\section{Materials and Methods}

\section{Study design and area}

This was an analytical study in which 51 complex cases of obstetric fistula were collated and analyzed and the prevailing risk factors
Correspondence: Dr. Emmanuel C. Inyang-Etoh, Dept. of Obstetrics and Gynaecology, University of Uyo Teaching Hospital, PMB 1136, Uyo, Akwa Ibom State, Nigeria.

Tel.+ 234.7034038318 - 234.8033452822.

E-mail: emmacol2000@yahoo.com

Key words: vesicovaginal fistula, patient selection, successful repair.

Acknowledgements: the authors acknowledge with a sense of indebtedness the kind gesture of Sr. (Dr.) Mary Morloy, the surgeon in charge of the fistula centre for permitting us to carry out this study at the centre. They want to also express their unreserved gratitude to Dr. John Kelly, a visiting expatriate expert fistula surgeon for giving us the permission to use his patients for this study.

Contributions: AJU, research study and design; ECIE, data analysis and interpretation.

Conflict of interest: the authors report no conflicts of interest.

Received for publication: 25 May 2011.

Accepted for publication: 11 October 2011.

This work is licensed under a Creative Commons Attribution NonCommercial 3.0 License (CC BYNC 3.0).

(C) Copyright A.J. Umoiyoho and E.C. Imyang-Etoh, 2011 Licensee PAGEPress, Italy

Urogynaecologia 2011; 25:e8

doi:10.4081/uij.2011.e8

identified. A scoring system was designed to aid in the selection of relatively simple cases suitable for repair by available fistula surgeons at the Family Health Centre located at Mbribit Itam, Uyo, Akwa Ibom State of Nigeria. Mbribit Itam is a semi-urban community in the outskirts of Uyo, the state capital of Akwa Ibom State, which is in the south-east health zone of Nigeria. This centre receives all cases of genital fistula from Akwa Ibom State and the neighbouring states of the south-east health zone of Nigeria.

In Nigeria, about $50 \%$ of pregnant women receive antenatal care in hospitals and only about 35\% deliver in hospitals for various reasons. (Nigeria national demographic health survey 2008). A vast majority of Nigerian women prefer to deliver in unorthodox maternity centres for various socioeconomic and cultural reasons and maternity care in such centres are often inadequate.

\section{Recruitment and data collection}

In a given 12-months period before the study, 241 unselected cases of vesicovaginal fistulas were repaired at the Family Health Centre by gynaecological and general sur- 
geons, who have been trained on fistula repair with a success rate of $79 \%$. The 51 cases that failed in the hands of these surgeons were assembled and analyzed and certain risk factors were identified. These complex cases were reserved for an expatriate (visiting) expert fistula surgeon. Using the identified risk factors, a prognostic scoring system was designed to assist in the selection of simple cases suitable for repair by non expert fistula surgeons subsequently. Each identified risk factor was awarded a score ranging from 0 to 4 depending on how it was adjudged empirically to affect the prospect of success following repair. In the following 12 months period, the scoring system was applied to 260 cases of obstetric fistula from which 42 cases were screened out and reserved for the expert fistula surgeon. The remaining 218 cases selected were then repaired by the same non-expert fistula surgeons with an increased success rate of $96 \%(\mathrm{OR}=6.294 ; 95 \% \mathrm{CI}=3.211-12.336)$.

There was a significant increase in the success rate following repair when the proposed prognostic scoring system was applied to select relatively simple cases. The data obtained were analyzed using descriptive and inferential statistics. Calculations were made using conventional statistical formulae.

\section{Results}

The fifty-one complex cases that failed initially in the hands of the non expert fistula surgeons were later repaired by the expatriate expert fistula surgeon with a success rate of $88 \%$. Each risk factor identified among these complex cases was awarded a score ranging from 0 to 4 depending on how it was adjudged empirically to affect the prospect of success following an attempt at repair. A scoring system was then designed to aid in the selection of relatively simple cases that can be repaired by gynaecological or general surgeons, who have been trained on fistula repair. The complex cases should be reserved for the more skilled and experienced expert fistula surgeons.

Table 1 shows the major risk factors and the cure rates attained in each case in the hands of the expert fistula surgeon. Many of the patients had two or more risk factors. The risk factors that were associated with high risk of failure following repair were adherence to the pubic bone, total urethral loss, 3 previous failures, combined vesicovaginal and rectovaginal fistulas as well as the presence of moderate to severe degree of scarring.

The proposed prognostic scoring system is shown in Table 2. The total score attainable is 29 and a score of 4 or less depicts a simple vesicovaginal fistula that can be repaired suc- cessfully by a gynaecological or general surgeon, who has been trained on fistula repair. Involvement of the urethra with circumferential defect, total urethral loss and 6 or more previous attempts at repair were identified as exceptionally high risk factors.

\section{Discussion}

The World Health Organization on its guiding principle on clinical management of vesicovaginal fistula has called for classification of obstetric fistula, which are defined as simple or complex fistulas based on operative difficulty. ${ }^{9}$ Many classifications proposed by research workers in this field are sheer anatomical descriptions of the fistula and this does not help in case prognostication. ${ }^{10-12}$ In contrast, the proposed scoring system is outcome-based and is intended to provide a guide that would help in the categorization of obstetric fistula into simple and complex based on our analysis of 51 complex cases, which initially failed in the hands of non expert fistula surgeons. These complex cases were later preferentially repaired by a visiting expatriate expert fistula surgeon with a success rate of $88 \%$. The success rate of $88 \%$ with these complex cases measured favourably with the success rates of $88 \%, 87.9 \%$ and $81.3 \%$ obtained in studies done in Ethiopia, Malawi and Benin city (Nigeria), respectively, for unselected cases. ${ }^{13-15}$ Even lower success rates of $73 \%$ was obtained in Niger republic and $75 \%$ in Maiduguri, Nigeria. ${ }^{16}$ The reasons for this disparity in success rates from different centres have not been adduced, however, it is probable that the cure rates obtained in different studies are a reflection of available surgical skill and experience at those centres. The proportion of complex cases present in each study population could have also influenced the general outcome as those studies were silent on patient selection

Table 2. Proposed prognostic scoring system for vesicovaginal fistula.

\begin{tabular}{|c|c|c|c|c|c|}
\hline Risk factors & & & Scores & & \\
\hline & 0 & 1 & 2 & 3 & 4 \\
\hline Site of fistula & Midvaginal & Juxtaurethral & Juxtacervical & Adherent & - \\
\hline & & & & to the pubis & - \\
\hline Size of fistula & $<2 \mathrm{~cm}$ & $2-4 \mathrm{~cm}$ & - & $>4 \mathrm{~cm}$ & \\
\hline Degree of scarring & $\mathrm{Ni}$ & Minimal & Moderate & Severe & - \\
\hline No. of previous failures & Nil & Once & 2 or 3 & 4 or 5 & $\geq 6$ \\
\hline $\begin{array}{l}\text { Involvement of the urethra } \\
\text { with circumferential defect }\end{array}$ & - & - & $<2 \mathrm{~mm}$ & $2-10 \mathrm{~mm}$ & $>10 \mathrm{~mm}$ \\
\hline Urethral loss & - & - & - & Proximal half & Complete \\
\hline No. of vesicovaginal fistula & 1 & - & $\geq 2$ & - & - \\
\hline $\begin{array}{l}\text { Proximity of fistula margin } \\
\text { to the ureter }\end{array}$ & Nil & $>25 \mathrm{~mm}$ & $\leq 25 \mathrm{~mm}$ & On margin & - \\
\hline Combined with RVF & Nil & Low RVF & High/mid RVF & - & - \\
\hline
\end{tabular}

RVF, rectovaginal fistula.

and the level of expertise of the surgeons that repaired the fistulas.

Based on the proposed prognostic scoring system, a score of 4 or less depicted a simple fistula which was empirically adjudged suitable for repair by gynaecological or general surgeons who have been trained on fistula repair. Cases with scores of 5 or more should be referred or reserved for expert fistula surgeons because of anticipated high risk of failure in less experienced hands. This strategy is imperative as the first attempt at repair provides the best opportunity for successful repair, besides, more surgeons could be mobilized and trained to repair simple cases. This is essential considering the revelation that only few surgeons currently engaged in fistula repair in Nigeria and the huge back-log of

Table 1. Risk factors and cure rates after repair among women in the study.

\begin{tabular}{lcc} 
Risk factors & $\begin{array}{c}\text { No. } \\
\text { of women } \\
(\%)\end{array}$ & $\begin{array}{c}\text { Cure } \\
\text { rate } \\
(\%)\end{array}$ \\
Juxtacervical & $10(19.6)$ & 70 \\
Juxtaurethral & $2(3.9)$ & 100 \\
\hline Midvaginal & $7(13.7)$ & 75 \\
Vesicocervical & $2(3.9)$ & 100 \\
\hline Urethrovaginal & $2(3.9)$ & 100 \\
Size $>4$ cm & $17(33.3)$ & 62.5 \\
\hline Total urethral loss & $7(13.7)$ & 28.6 \\
Involvement of the & $3(5.9)$ & 100 \\
urethra with & & \\
circumferential loss & & \\
\hline Adherent to the pubic bone & $1(1.9)$ & 0.0 \\
$>3$ previous failures & $10(19.6)$ & 37.5 \\
\hline Moderate/severe scarring & $11(21.5)$ & 44.4 \\
$>$ lvesicovaginal fistulas & $2(3.9)$ & 100.0 \\
\hline $\begin{array}{l}\text { Requiring ureteric } \\
\text { re-implantation }\end{array}$ & $1(1.9)$ & 100.0 \\
Combined with high RVF & $12(23.5)$ & 41.7 \\
\hline RVF, rectovaginal fistula. & & \\
\hline
\end{tabular}


management of an obstetric fistula, is patient selection based on the complexity of the case and available surgical expertise. fistulas in areas where obstetric fistula is highly prevalent could also be considered.

It is also important to note that all the risk factors need not be present in any given patient. The presence of 2 to 4 associated factors in one patient is not uncommon. Associated factors that were particularly associated with high risk of failure were large or total urethral loss, adherence of the fistula to the pubic bone and three or more previous failed attempts at repair. Other high risk factors were co-existing high-type rectovaginal fistula and the presence of moderate to severe degree of scarring. We suggest that whenever any of these high risk factors are present in an individual patient, such a patient should be referred or reserved for an expert fistula surgeon for appropriate management. Even when the fistula may not be amenable to surgical closure, the expert fistula surgeon is best suited to carry out a continent urinary diversion surgery if necessary.

Although, the application of this proposed prognostic scoring system in patient selection in our series has proved promising, there is a need for long term evaluation of this scoring system to authenticate its validity.

In conclusion, the proposed prognostic scoring system is designed to provide a guide that would help in the selection of simple vesicovaginal fistulas that could be repaired by general or gynaecological surgeons, who have been trained on fistula repair with significant prospect of success. The first step towards the

\section{References}

1. World Health Organization. Health dimensions of sex and reproduction: the global burden of disease. Geneva, Switzerland, WHO 1998.

2. Vangeenderhuysen C, Prual A, Ould el Joud D. Obstetric fistula: incidence estimates for sub-saharan Africa. Int $\mathrm{J}$ Gynaecol Obstet 2001;73:65-6.

3. United Nations Population Fund (UNFPA). Nigerian fistula Fortnight United Nations Technical report 2006.

4. United Nations Population Fund (UNFPA), Engender Health. Obstetric fistula needs assessment: findings from nine African countries, pp. 57-76. New York, USA, UNFPA 2003.

5. Wall L.L. Obstetric VVF as an international public health problem. Lancet 2006;368: 1201-9.

6. Arrowsmith D. Genitourinary reconstruction in obstetric fistulas. J Urol 1994; 152:403-6.

7. Gutman RE, Dodson JL, Mostwin JL. Complications of treatment of obstetric fistula in the developing world: gynaetresia, urinary incontinence and urinary diversion. Int J Gynaecol Obstet 2007;99: S57-64.
8. Wall LL, Arrowsmith S, Briggs N, Lassey A. Urinary incontinence in the developing world: the obstetric fistula. In: P. Abrams, L. Cardozo, S. Khoury and A. Wein (eds.) pp. 893-935. Plymouth, UK, Health Publication Ltd 2002.

9. de Bernis L. Obstetric fistula: guiding principle for clinical management and programme development, a new WHO guideline. Int J Gynaecol Obstet 2007;99:S11721.

10. Waaldijk K. Surgical classification of obstetric fistulas. Int $\mathrm{J}$ Gynaecol Obstet 1995;49:161-3.

11. Goh JT. A new classification for female genital tract fistula. Aust $\mathrm{N} \mathrm{Z} \mathrm{J} \mathrm{Obstet}$ Gynecol 2004;44:502-4.

12. Arrowsmith SD. The classification of obstetric vesico-vaginal fistulas: A call for an evidence-based approach. Int J Gynaecol Obstet 2007;99:S25-7.

13. Kelly J, Kwast BE. Epidemiologic study of VVF in Ethiopia. Int Urogynaecol J 1993; 5:278-81.

14. Rijken Y, Chilopora GC. Urogenital and rectovaginal fistula in southern Malawi: A report on 407 patients. Int $\mathrm{J}$ Gynaecol Obstet 2007;99:S85-9.

15. Gharoro EP, Abedi HO. Vesicovaginal fistula in Benin-City, Nigeria. Int $\mathrm{J}$ Gynaecol Obstet 1999;64:313-4.

16. Nafion I, Idrissa A, Ghaichatou AK, et al. Obstetric vesico-vaginal fistulas at the National Hospital of Niamey, Niger. Int $\mathbf{J}$ Gynaecol Obstet 2007;99:S71-4. 